\title{
Traços paleográficos de receitas culinárias novecentistas: uma análise no âmbito da Crítica Textual
}

\section{Palaeographic traces of twentieth-century culinary recipes: an analysis in the context of Textual Criticism}

\author{
Marcos Alexandre dos Santos* \\ Universidade Federal de Minas Gerais, Belo Horizonte, MG, Brasil \\ Márcia Cristina de Brito Rumeu** \\ Universidade Federal de Minas Gerais, Belo Horizonte, MG, Brasil
}

\begin{abstract}
Resumo: Neste trabalho, objetivamos descrever aspectos paleográficos de receitas culinárias produzidas no início do século XX e atualmente resguardadas no Acervo dos Escritores Mineiros da UFMG. Com base nas conservadoras edições fac-similar e semidiplomática de tais receitas culinárias confeccionadas por Santos (2018), passamos à descrição da morfologia das letras em relação ao ângulo, módulo e peso do traçado (Spina, 1977; Nuñez Contreras, 1994; Berwanger; Leal, [1995]2008), visto que temos em foco um único traçado no decorrer dos 89 fólios opistógrafos organizados em um pequeno códice. Entendemos que, de um modo geral, a relevância desta discussão esteja não só no potencial histórico das receitas culinárias, mas também na sua evidência como fonte do português brasileiro escrito do início do século XX.
\end{abstract}

Palavras-chave: Receitas culinárias históricas. Paleografia. Edição fac-similar. Edição semidiplomática.

\begin{abstract}
This article aims to describe paleographic aspects of a book containing handwritten culinary recipes from the beginning of the $20^{\text {th }}$ century, which is currently preserved in the Collection of Mineiros' Writers (Acervo de Escritores Mineiros) at the Federal University of Minas Gerais (UFMG). Based on the facsimile and conservative edition of these recipes made by Santos (2018), we focus on the morphologic features of the handwriting, such as the angle, the module and the weight of the tracing (Spina, 1977; Nuñez Contreras, 1994; Berwanger; Leal, [1995]2008), since there is only one handwriting throughout the 89 opisthographic folios organized in a small codex. We understand that, in general, the relevance of this discussion is not only measured by the historical potential of the culinary recipes, but also lies in its importance as an evidence and material source of the written Brazilian Portuguese from the beginning of the $20^{\text {th }}$ century.
\end{abstract}

Keywords: Historical culinary recipes. Paleography. Facsimile edition. Semidiplomatic edition.

\footnotetext{
* Graduando do Curso de Bacharelado em Língua Portuguesa com ênfase em Edição, Universidade Federal de Minas Gerais - UFMG, MG, Brasil; m.alexandre.s@outlook.com

** Professora Associada, Área de Língua Portuguesa, Universidade Federal de Minas Gerais - UFMG, MG, Brasil; mrumeu@ufmg.br
} 


\section{CONSIDERAÇÕES INICIAIS}

Neste artigo, pretendemos descrever alguns aspectos paleográficos de receitas culinárias novecentistas (1906) já editadas de forma fac-similar e semidiplomática (nos termos de Spina, 1977) por Santos (2018). Acreditamos que a principal contribuição desta conservadora edição de manuscritos novecentistas esteja ancorada na hipótese defendida por Tarallo (1993, p. 99) de que "o cidadão brasileiro já estava de posse, ao final do século XIX, de sua própria língua/gramática", o que permite conjecturar que as receitas culinárias representem um testemunho do português brasileiro (doravante PB) em sua expressão escrita de sincronias passadas. Nesse sentido, assumimos que a relevância desta análise esteja não só no valor histórico das receitas culinárias, mas também na sua expressão como fonte do PB escrito do início do século XX.

Acreditamos que as edições fac-similar e semidiplomática permitam aos consulentes e aos linguistas não só confirmarem ou infirmarem a interpretação do código escrito através da possibilidade de contato com o fac-símile, mas também evidenciarem o respeito a todas as práticas paleográficas e linguístico-textuais específicas (edição semidiplomática) de um conjunto de receitas culinárias compiladas no início do século XX. Nesse sentido, assumimos que o caráter conservador da edição das receitas culinárias (nos moldes de Rumeu 2013; Lobo, 2001) possa refletir, com um maior nível de fidedignidade, o PB de sincronias passadas em sua expressão escrita.

O pequeno códice ${ }^{1}$ das receitas culinárias novecentistas em análise é composto por 89 fólios opistógrafos ${ }^{2}$, cuja distribuição os evidencia com 45 e 44 fólios pautados, produzidos nos seus recto e verso, respectivamente, cujas dimensões são $107 \mathrm{~mm}$ de largura por $156 \mathrm{~mm}$ de altura para cada fólio. Trata-se de um pequeno conjunto de receitas culinárias devidamente organizadas a partir de um índice das receitas exposto no final do caderno e catalogadas com a referência às "receitas culinárias de 1906", resguardadas no Acervo de Escritores Mineiros da UFMG (AEM), no âmbito da Biblioteca Central da UFMG. No primeiro e no último fólio do códice (fól. 45r) em análise, há a menção ao local (Ouro Preto) e à data (21 de julho de 1906), sem que haja informações mais precisas acerca da cronologia da cópia de época no pequeno códice. Além dessas menções ao local e à data (no primeiro e no último fólios, conforme as figuras 1 e 2), observamos a referência a dois antropônimos (no primeiro fólio) ${ }^{3}$, possivelmente relacionados a integrantes de famílias mineiras, já que tal conjunto de receitas culinárias encontra-se envolvido sob o rótulo de "receitas de vovós mineiras".

\footnotetext{
${ }^{1}$ Por códice entendemos "[...] Um livro manuscrito organizado em cadernos solidários entre si por cosedura e revestidos por uma encadernação [...]”, conforme Faria e Pericão (2008, p. 267).

2 Assumimos opistógrafo como em “[...] seu sentido original designava 'escrita pelas costas'. Diz-se da obra cujas páginas estão manuscritas ou impressas dos dois lados do suporte; opõe-se a anopistógrafo.” (Faria; Pericão, 2008, p. 893).

3 Neste trabalho, optamos por proteger as identidades das pessoas envolvidas, referenciando os antropônimos mencionados a partir das suas letras iniciais (Dona BM e A).
} 


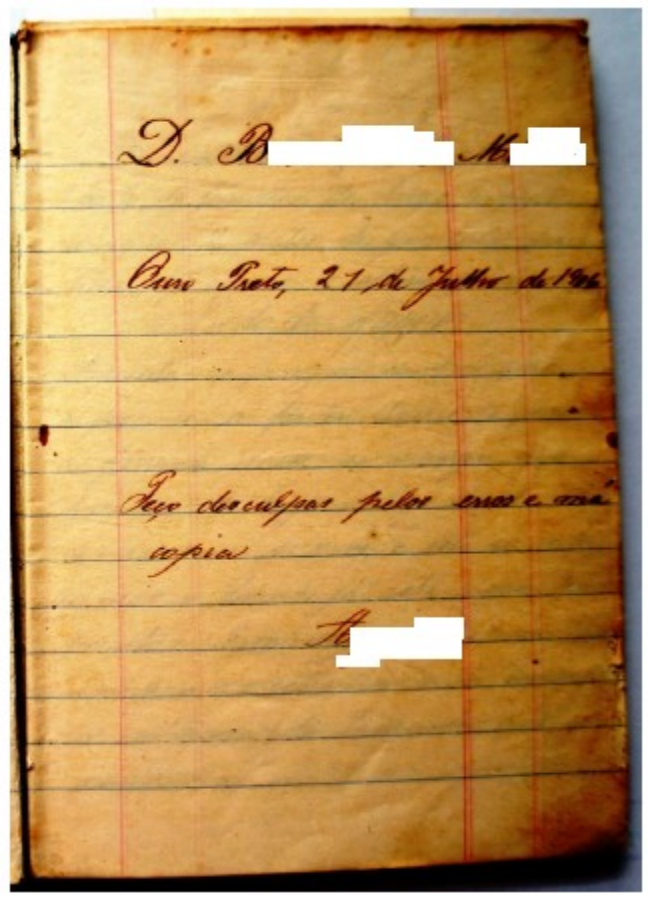

Figura 1 - "Folha de rosto" do caderno de receitas novecentistas.

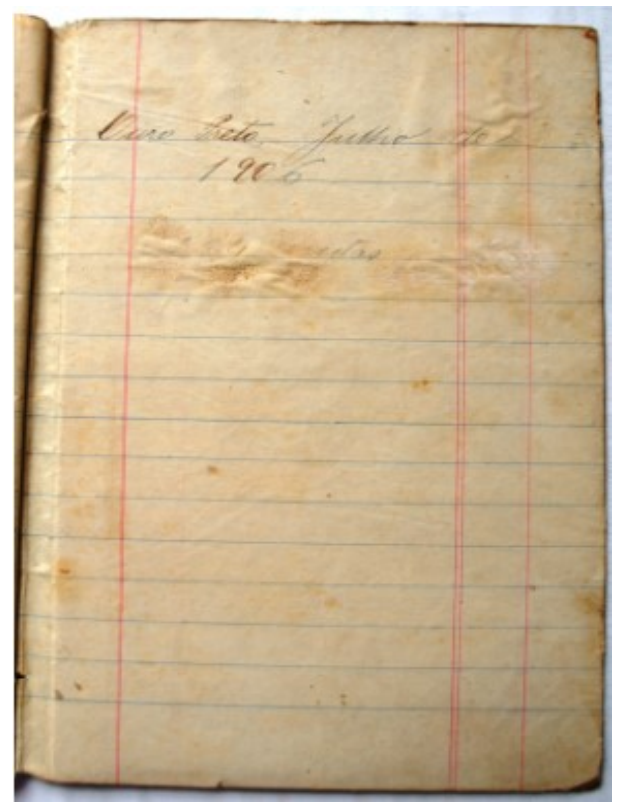

Figura 2 - Último fólio [fól. 45r] em que há a menção ao local (Ouro Preto), ao mês (julho), ao ano (1906) e ao número de receitas (124 receitas).

Estruturalmente, este artigo está organizado em duas seções. $\mathrm{Na} 1^{a}$ seção, não só circunscrevemos o trabalho de edição em análise como fac-similar e semidiplomática, mas também apresentamos os critérios que orientaram o processo de edição. $\mathrm{Na} 2^{a}$ seção, passamos à descrição de alguns aspectos paleográficos das receitas culinárias novecentistas, relacionados à morfologia das letras. Por fim, apresentamos, nas considerações finais, alguns aspectos como possíveis pautas para futuros estudos linguísticos com base nas receitas culinárias em foco. 


\section{O TRABALHO DE EDIÇÃO DE MANUSCRITOS NOVECENTISTAS: AS EDIÇÕES FAC- SIMILAR E SEMIDIPLOMÁTICA E OS CRITÉRIOS DE EDIÇÃO DAS RECEITAS CULINÁRIAS NOVECENTISTAS}

A opção pelas edições fac-similar e semidiplomática das receitas culinárias merece ser pormenorizada, à luz dos princípios teórico-metodológicos da Crítica Textual (Spina, 1977; Nuñez Contreras, 1994; Berwanger; Leal, [1995] 2008; Spaggiari; Perugi, 2004; Cambraia, 2005), tendo em vista, na segunda seção deste artigo, a descrição de alguns aspectos paleográficos do texto novecentista em análise. Assim sendo, pretendemos argumentar, nesta seção, sobre a preferência pelas edições fac-similar e semidiplomática de receitas culinárias novecentistas, atentando também para a apresentação dos parâmetros de edição.

\subsection{A opção pelas edições fac-similar e semidiplomática}

Tendo em vista a polissemia do termo filologia, já amplamente discutida por Vasconcellos; Santiago-Almeida (2012, p. 336), Santiago-Almeida (2009, p. 223), Cambraia (2005), Carvalho e Silva (1994), assumimos que cabe ao filólogo o trabalho com o texto escrito de uma forma mais ampla e diversificada (Vasconcellos; Santiago-Almeida, 2012, p. 336), já que "a palavra filólogo, pela sua polissemia, não se aplica exclusivamente a quem se dedica à crítica textual" (Carvalho e Silva, 2002, p. 70). Por outro lado, entendemos, em conformidade com Carvalho e Silva (1994) à luz da filóloga Luciana Stegagno Picchio, que cabe ao crítico textual a reconstituição textual em sentido amplo, não atuando tão somente como um "mero preparador de textos a serem entregues depois, prontos para a interpretação, a um pesquisador de grau superior, identificável com o crítico literário" (Carvalho e Silva, 1994, p. 61). Nesse sentido, acolhemos as seguintes preocupações que também passam pelo crivo atento do crítico textual (Carvalho e Silva, 1994).

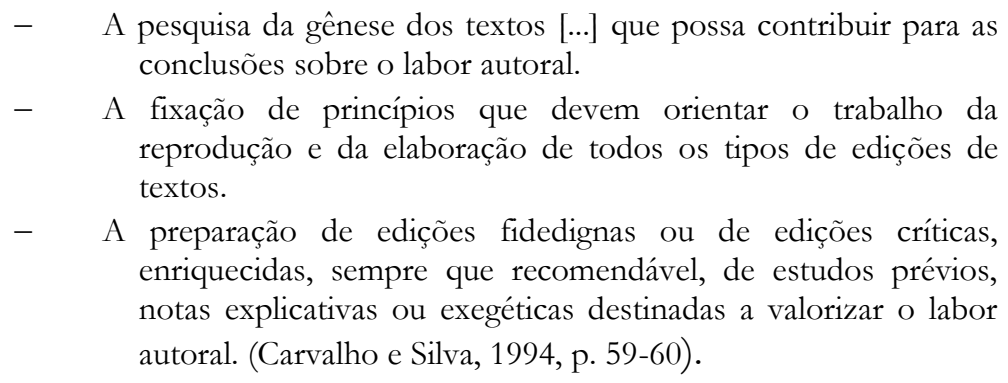

Uma vez explicitada a distinção entre os conceitos de filologia e crítica textual com base nas funções do filólogo e do crítico textual, passamos a uma breve caracterização, à luz de Spina (1977), das edições fac-similar e semidiplomática propostas para as receitas culinárias novecentistas. Tendo em vista o fato de que este trabalho de edição está orientado pelo objetivo maior de contribuir para a formação de amostras históricas do PB escrito em sincronias passadas, acreditamos que a peculiaridade do gênero textual receitas culinárias esteja justamente no fato de tal conjunto de receitas ter sido escrito em 1906. Nesse sentido, considerando tratar-se de uma amostra sui generis para o estudo do PB escrito, justifica-se a confecção de uma conservadora edição de tais receitas culinárias provavelmente produzidas por punhos mineiros no início do século $\mathrm{XX}$, o que justifica também o seu vínculo ao Projeto de Pesquisa "Para uma Sociolinguística Histórica do Português Brasileiro: 
variação sincrônica e mudança diacrônica", desenvolvido na Faculdade de Letras da UFMG. Partindo do pressuposto de que a edição das receitas culinárias em análise servirá aos futuros estudos linguísticos, buscamos oferecer ao leitor a possibilidade de conferir até que ponto a interpretação do editor acerca do grafema ${ }^{4}$ manuscrito está ou não de acordo com a imagem do seu fac-símile (edição fac-similar). Comprometemo-nos ainda com uma edição desprovida de intervenções e/ou modernizações no decorrer do processo de transcrição dos originais manuscritos (edição semidiplomática/diplomático-interpretativa, nos termos de Spina (1977, p. 79)).

- EDIÇÃO FAC-SIMILADA - A que reproduz a edição original exatamente, quer no texto, quer nas ilustrações; costuma-se fazer-se de textos com valor documental, particularmente de textos manuscritos que se reproduzem por processos fotomecânicos. (Faria; Pericão, 2008, p. 432).

- EDIÇÃO DIPLOMÁTICO-INTERPRETATIVA - Edição de carácter diplomático apresentando ligeiras adaptações que não atingem a substância do texto (desdobramento de abreviaturas [...] por exemplo). (Faria; Pericão, 2008, p. 430).

Com o intuito de ilustrarmos o trabalho de edição das receitas culinárias novecentistas em si, apresentamos, na figura 3, o layout da edição em análise, com o fac-símile ao lado da sua transcrição, o que a legitima como fac-similar e semidiplomática (Faria; Pericão, 2008).
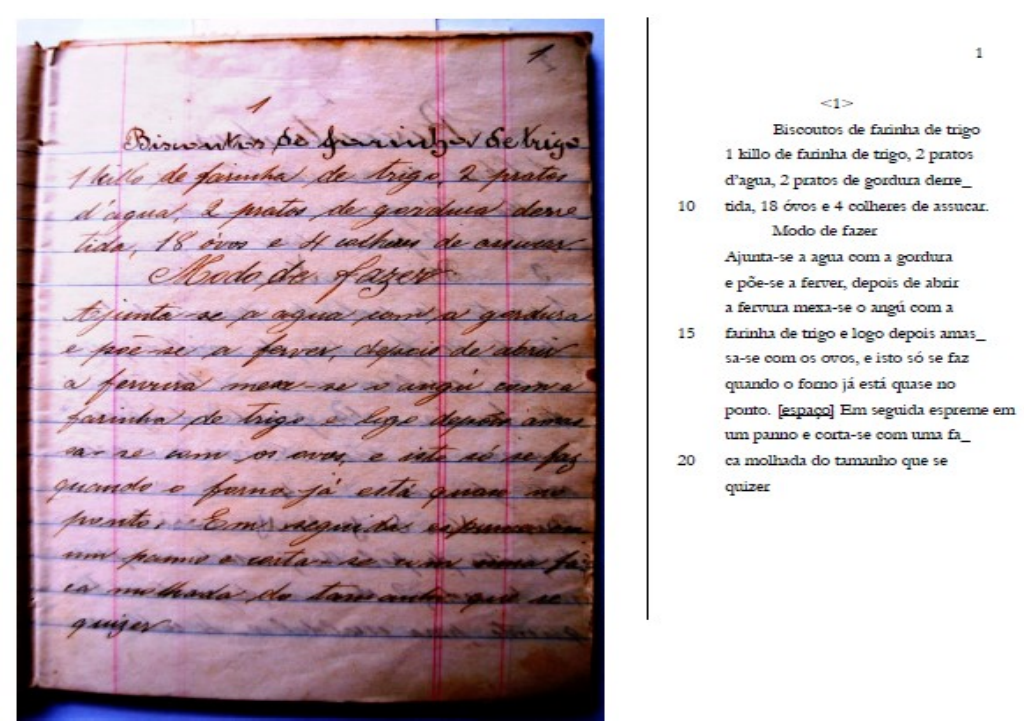

Figura 3 - As edições fac-similar e semidiplomática das receitas culinárias novecentistas.

Assumimos, ao conjugar o fac-símile à edição semidiplomática, que esse tipo de edição serve aos estudos linguísticos acerca do PB escrito bem no início do século $\mathrm{XX}$, visto que permite ao leitor confirmar ou infirmar a decifração do grafema através da possibilidade de leitura do manuscrito.

\footnotetext{
4 Por grafema entendemos "Em filologia, a unidade mínima, discreta, do sistema da escrita." (Faria; Pericão, 2008, p. 599).
} 


\subsection{As edições fac-similar e semidiplomática das receitas culinárias novecentistas: critérios de edição}

Em uma perspectiva conservadora para a edição das receitas culinárias novecentistas (Lima; Marcotulio; Rumeu, 2019), prevemos os seguintes procedimentos metodológicos gerais: (I) as fronteiras de palavras foram resguardadas; (II) os sinais gráficos de pontuação e os diacríticos foram fielmente mantidos e (III) as distinções entre letras maiúsculas e minúsculas também foram preservadas tal como no original manuscrito. Esclarecemos, em notas de rodapé, quaisquer práticas linguístico-textuais da época ou específicas do redator, bem como também atentamos aos possíveis lapsos de escritura do escrevente, a fim de otimizarmos o trabalho de depreensão do código escrito por um leitor contemporâneo. Acrescentemos ainda que a edição das receitas novecentistas deu-se com base em parâmetros específicos de transcrição dos manuscritos inspirados principalmente em Rumeu (2013) e Lobo (2001), orientadas para o Projeto Para a História do Português Brasileiro ${ }^{5}$. Na sequência, exemplificamos alguns dos parâmetros de transcrição legitimados pelo fac-símile em questão para a devida análise.

(a) A divisão de linhas e a mudança de fólios foram preservadas tais como se deixam evidenciar no manuscrito original. Quando houve mudança de fólio, optamos por marcar, entre colchetes, no canto superior direito, as referências ao número do fólio e ao seu recto ou ao verso, como se observa na figura 4.

(b) As linhas na transcrição foram numeradas de cinco em cinco a partir da quinta. Tal numeração está localizada na margem direita da mancha gráfica (conforme também identificado na figura 4).

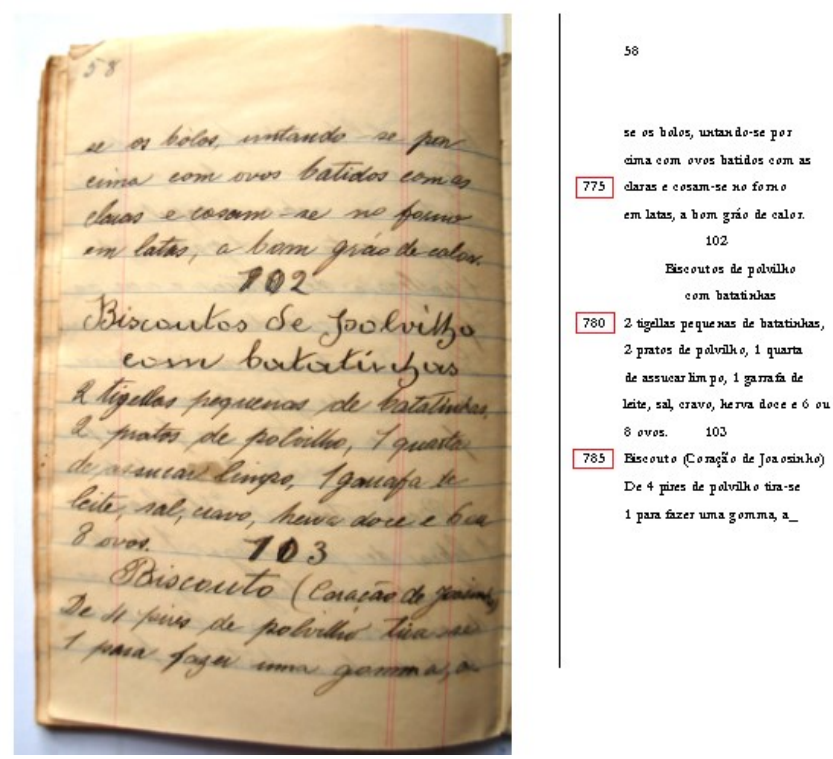

Figura 4 - Transcrição do fólio 30 verso: a referência ao fólio.

\footnotetext{
5 Parâmetros de transcrição discutidos no II Seminário do Projeto Para a História do Português Brasileiro, realizado em Campos do Jordão, no período de 10 a 16 de maio de 1998, pela comissão de pesquisadores composta por Heitor Megale (USP), César Nardelli Cambraia (USP), Gilvan Müller de Oliveira (UFSC), Marcelo Módolo (mestrando-USP), Permínio Ferreira (UFBA), Sílvio de Almeida Toledo Neto (USP), Tânia Lobo (UFBA) e Valdemir Klamt (UFSC).
} 
(c) Os sinais gráficos de pontuação foram mantidos tal como reproduzidos pela copista. Em caso de intervalos entre as palavras maiores do que o padrão, usamos a indicação [espaço]. $\mathrm{Na}$ imagem referente ao fólio $7 \mathrm{r}$ (figura 5), identificamos com o número (1) um espaçamento maior entre as palavras que o usual no corpo deste texto. Em (2), identificamos o espaço em branco que normalmente identifica os itens lexicais e gramaticais da língua portuguesa e para o qual não houve indicação alguma na transcrição (figura 5).

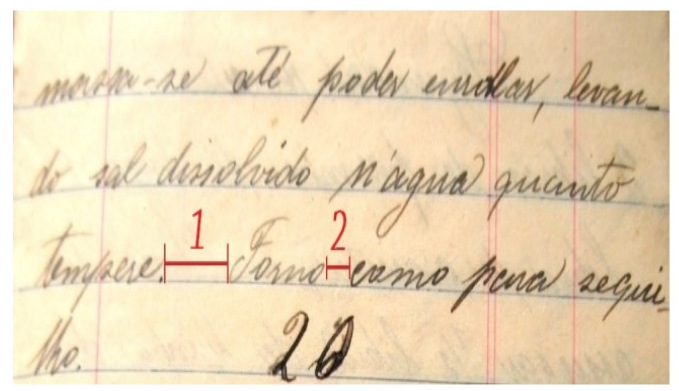

massa-se até poder enrolar, levando sal dissolvido n'agua quanto tempere [espaço] Forno para sequitho.

20 [fól. 7r: 158-161]

Figura 5 - Fac-símile e transcrição: a referência a um [espaço] intervalar maior entre as palavras.

(d) Os acentos gráficos foram preservados exatamente como foram produzidos pela copista, conforme as figuras 6 e 7 .

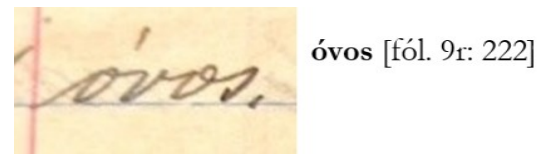

Figura 6 - O acento no item lexical "óvos".

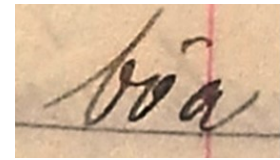

bôa [fól. 1r: 296]

Figura 7 - O acento no item lexical "bôa".

(e) As letras maiúsculas e minúsculas foram mantidas exatamente como mostraram-se no manuscrito. Evidenciamos, na figura 8, a redação da palavra "loth" com inicial minúscula ("l" minúsculo). Na figura 9, por outro lado, observamos que a redação do mesmo item lexical "Loth" deu-se com letra inicial maiúscula ("l" maiúsculo).

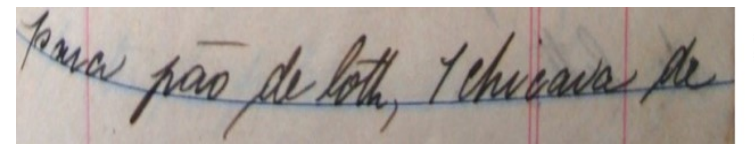

para pão de loth, 1 chicara de

[fól. 19r: 539]

Figura 8 - A grafia do item lexical "loth" com "l" minúsculo.

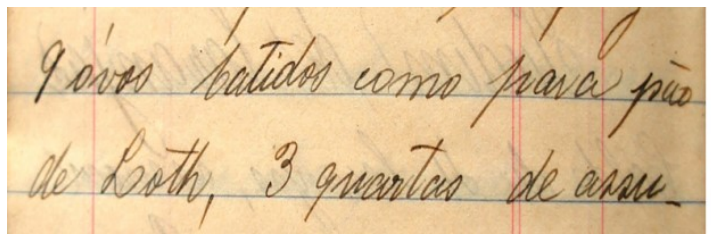

9 óvos batidos como para pão de Loth, 3 quartas de assu-

[fól. 37v: 989-990]

Figura 9 - A grafia do item lexical "Loth" com "L" maiúsculo. 
(f) Eventuais "erros" e/ou especificidades da produção escrita foram devidamente comentados em nota de rodapé, conforme ilustrado nas figuras 10,11 e 12.

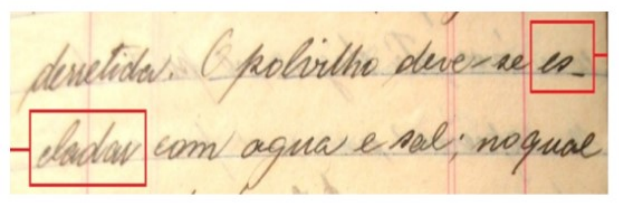

derretida. O polvilho deve-se es-

cladar $^{19}$ com agua e sal; no qual

$[\cdots]$

${ }^{19}$ Leia-se "escladar" por "escaldar"

Figura 10 - A grafia do item lexical "escaldar": um caso de metátese.

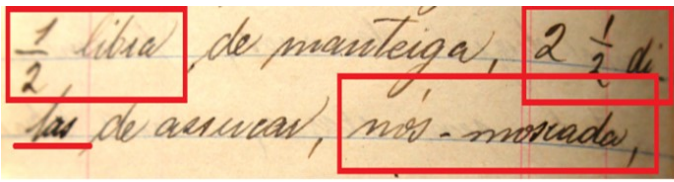

$1 / 2$ libra $^{1}$ de manteiga, $21 / 2$ di tas $^{2}$ de assucar, nós ${ }^{3}-$ moscada,

${ }^{1}$ Leia-se "libra" como unidade de medida do séc. XIII equivalente a 0.4590 gramas, cf. Lopes (2005, p. 45)

${ }^{2}$ Leia-se "dita" como unidade de medida.

${ }^{3}$ Leia-se "nós-moscada" por "noz-moscada".

[fól. 33v: 866-867]

Figura 11 - Especificidades da produção escrita: as unidades de medida (libra, dita) e a grafia do item "noz-moscada".

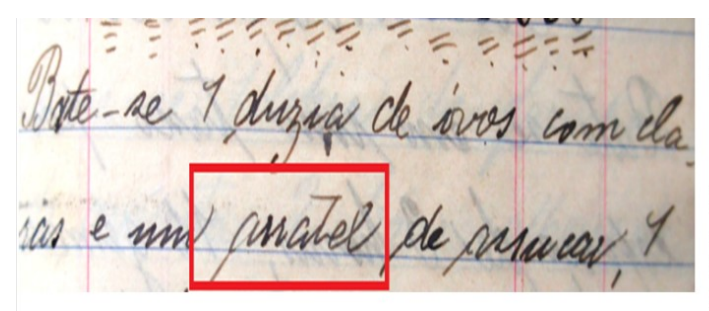

Bate-se 1 duzia de óvos com claras e um arrate ${ }^{1}$ de assucar, 1 [...]

[fól. 23r: 651-652]

$\overline{{ }^{1} \text { Antiga unidade }}$ de medida de peso de acordo com sistema português de medidas de D. Manuel, correspondendo a 0.4590 gramas, cf. Lopes $(2005$, p. 45).

Figura 12 - Especificidades da produção escrita: arratel (unidade de medida).

(g) Inserções da copista em locais como a entrelinha ou margens (inferior, superior ou laterais) foram marcadas entre os sinais $<>$ (margens) (conforme identificado na figura 13), $<\downarrow>$ (entrelinha inferior à linha do texto) ou então $<$ $\uparrow>$ (entrelinha superior à linha do texto).

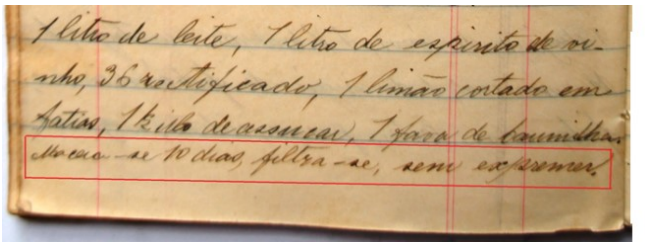

1 litro de leite, 1 litro de espirito de vinho, 36 retificado, 1 limão cortado em fatias, 1 killo de assucar, 1 fava de baunilha $<$ Macera-se 10 dias, filtra-se, sem expremer. $>$ [fól. 39v: 1059]

Figura 13 - Inserções do copista na margem inferior.

(h) Intervenções de terceiros foram marcadas entre os sinais $<>$ e explicadas em nota de rodapé (figura 14).

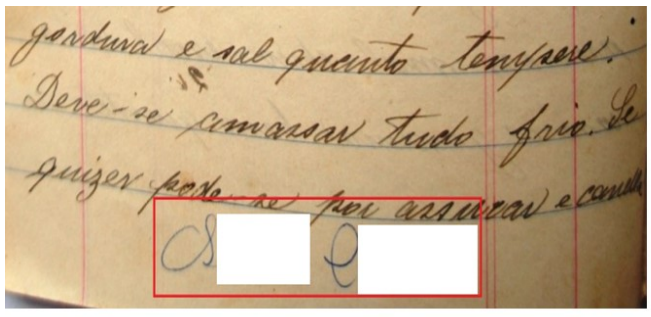

gordura e sal quanto tempere.

Deve-se amassar tudo frio. Se

quizer pode-se por assucar e canella. $<$ S. C. $>1$

${ }_{1}$ Referência ao antropônimo S. C que, por sua vez, remete à coleção em que esse conjunto de receitas se encontra resguardado no AEM/UFMG.

[fól. 8V: 216-218]

Figura 14 - Intervenções de terceiros no manuscrito. 
(i) $\mathrm{O}$ editor somente fez intervenções no texto para esclarecer dúvidas de extrema necessidade, indicando tal interferência entre colchetes e em itálico, ou então para indicar uma possível incompreensão na leitura de algum termo. Nesse sentido, a proposta foi usarmos [inint.] como indicação de ininteligivel.

(j) Quaisquer informações relacionadas a aspectos gerais do manuscrito, tais como diagramação e layout do texto, foram especificados em notas de rodapé, como está exposto na figura 15 .

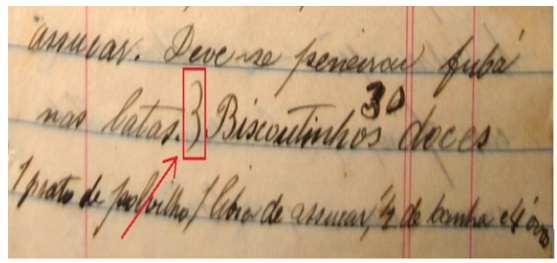

assucar. Deve-se peneirar fubá nas latas. $\}^{1}$ Biscoutinhos $\left.<\uparrow 30\right\rangle$ doces

1 prato de polvilho, 1 libra de assucar, 4 de banha e $4<\downarrow$ óvos >

${ }^{1}$ Sinal gráfico " $\}$ " que parece ter sido usado para a separação do texto da receita n. 29 do título da próxima receita (a 30a receita)

[fól. 9r: 232-234]

Figura 15 - Informações gerais sobre diagramação e layout vêm em nota de rodapé.

Uma vez expostos os parâmetros de transcrição das receitas culinárias novecentistas, passamos, inicialmente, à definição de paleografia, às suas especificidades e, na sequência, à descrição-analítica de alguns aspectos paleográficos voltados para a caracterização do ductus em relação ao ângulo, módulo e peso do traçado.

\section{RECEITAS CULINÁRIAS NOVECENTISTAS: ALGUNS APONTAMENTOS PALEOGRÁFICOS}

A definição de paleografia é o "estudo das antigas escritas e evolução dos tipos paleográficos" (Spina, 1977, p. 18). Ainda que Spina (1977) e Nuñez Contreras (1994, p. 19) dialoguem em relação à noção de paleografia como "un medio de lectura de escrituras en desuso", é interessante atentarmos para as considerações de Nuñez Contreras (1994) acerca das especificidades da paleografia. São elas: (I) a paleografia de leitura, (II) a paleografia crítico-analítica e (III) a paleografia como contribuição à bistória da escrita.

A paleografia de leitura e a paleografia para a bistória da escrita se retroalimentam, na dinâmica do exame de padrões de escrita vigentes em sincronias passadas, tendo em vista também a transformação dos modelos de escrita na história das línguas humanas, em conformidade com a definição de paleografia proposta por Spina (1977). Por outro lado, questões norteadoras da paleografia crítico-analítica (Nuñez Contreras, 1994), como o quando, o onde e o como (modus faciendi) o texto escrito foi produzido, orientam o trabalho do linguista-pesquisador interessado nas questões sociais que também impulsionam a variação e a mudança linguística nos eixos linguístico e social (embbeding problem, segundo Weinreich, Labov e Herzog, 1968). Assim sendo, conhecimentos paleográficos e sociolinguísticos interpõem-se no sentido da construção de uma sociolinguística histórica. Partimos da ideia de que a força propulsora da mudança linguística atuante outrora continua a influenciar a realidade linguística sincrônica como reflexo do princípio norteador da mudança nas línguas humanas - The uniformitarian principle (Labov, 1994). Admitimos assim que a realidade linguística presente deva representar o ponto de partida para a compreensão 
histórica do estatuto variável do $\mathrm{PB}$ em sincronias passadas (Historical paradox, conforme Labov, 1994, p. 11).

Considerando o fato de que trabalhamos com registros copiados de receitas culinárias cujas noções de espaço (Ouro Preto) e de tempo (21 de julho de 1906) foram expostas no próprio caderno de receitas culinárias novecentistas, admitimos que o foco da paleografia está justamente voltado para a descrição-analítica de aspectos específicos das escritas antigas, contribuindo, em última instância, para a reconstituição da história da escrita. Assim sendo, assumimos a definição de paleografia exposta por Nuñez Contreras (1994, p. 23), como "Ciencia que con un método propio estudia el desarrollo del proceso gráfico, considerada la escritura como una facultad propia y privativa del hombre." "Uma vez não só definida a paleografia, mas também expostas as suas especificidades (paleografia de leitura, paleografia crítico-analítica e paleografia com foco na história da escrita), passamos à descrição de alguns aspectos paleográficos das receitas culinárias novecentistas, conduzindo esta análise também por uma breve descrição sobre a morfologia das letras em relação ao peso, ao módulo e ao ângulo do seu ductus (Berwanger; Leal, [1995] 2008, p. 107).

\subsection{Aspectos paleográficos das receitas novecentistas: a morfologia e o ductus (traçado) das letras em cena}

Os oitenta e nove fólios opistógrafos das receitas culinárias novecentistas evidenciam letras "traçadas de um só lance e sem descanso de mão" (Acioli, 1994, p. 13), o que permite caracterizar o tipo de letra em questão como cursiva, cujo traçado deu-se de uma única vez pelo copista, com o traçado inclinado para a direita. Considerando que o ductus evidencia "as características do traçado da letra" (Berwanger; Leal, [1995] 2008, p. 107), constatamos que a letra das receitas novecentistas é arredondada e de traçado homogêneo, de um modo geral. A tinta das letras é de coloração castanha, ainda que em distintos tons, como os traçados das letras minúsculas e maiúsculas expostos nas figuras 16 e 17, respectivamente.

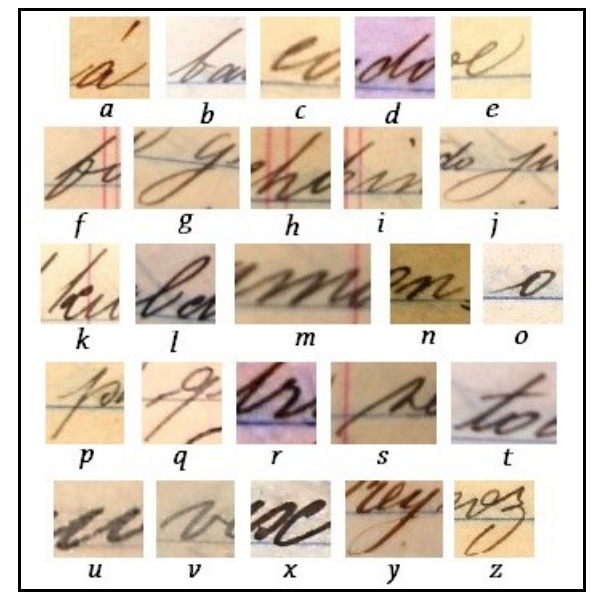

Figura 16 - Traçado das letras minúsculas.

\footnotetext{
6 "Ciência que com um método próprio estuda o desenvolvimento do processo gráfico, considerada a escrita como uma faculdade própria e privativa do homem" (Nuñez Contreras, 1994, p. 23, tradução nossa).
} 


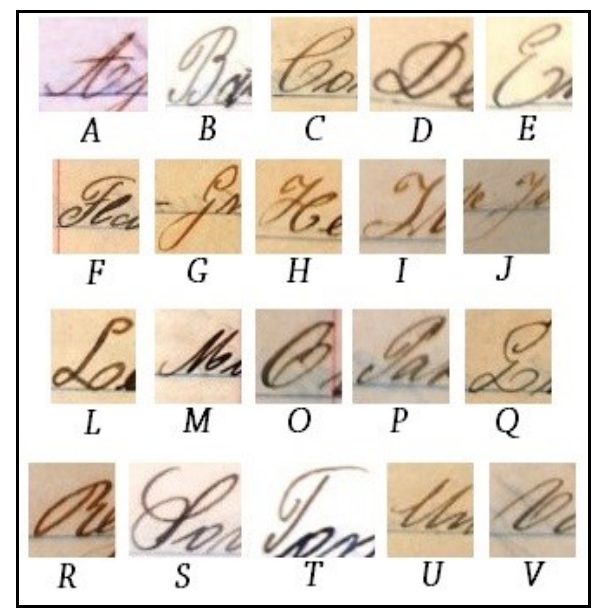

Figura 17 - Traçado das letras maiúsculas.

Os títulos de algumas das receitas culinárias em análise mostram-se ornamentados (figura 18), o que parece não só apontar para um copista que dominava o traçado escrito, mas também que tenham sido receitas copiadas por um mesmo punho, até porque a troca de punhos apenas na redação dos títulos das receitas evidenciaria uma tarefa um tanto quanto laboriosa na confecção da cópia do livro de receitas.
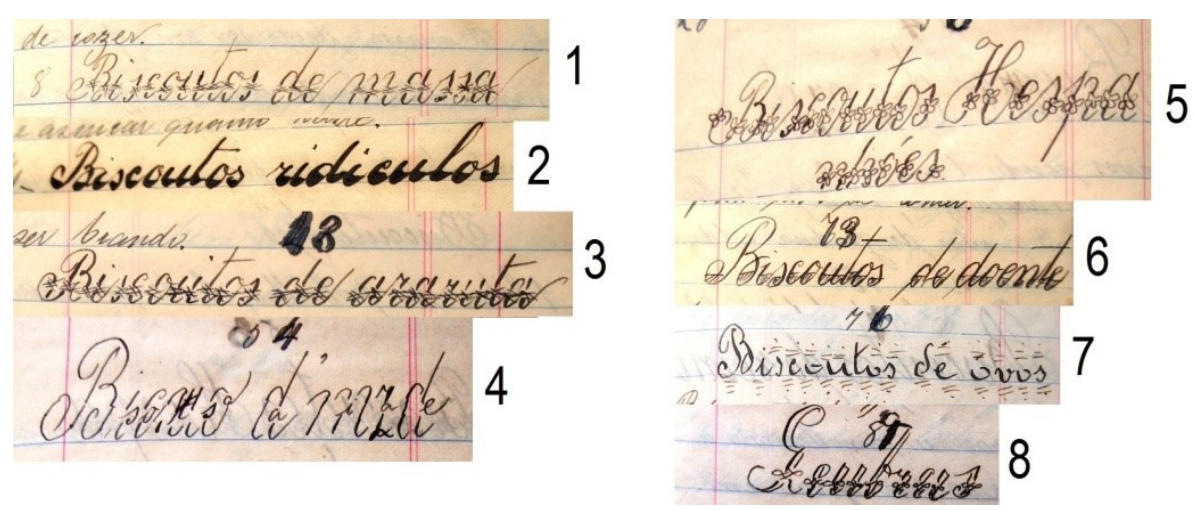

Figura 18 - Compilação de traçados ornamentados em alguns títulos das receitas culinárias novecentistas.

Como evidência de um registro escrito não formulaico como é o caso das receitas culinárias novecentistas, observamos, em alguns trechos, o desrespeito à delimitação das margens superior e inferior, atestado na figura 19.
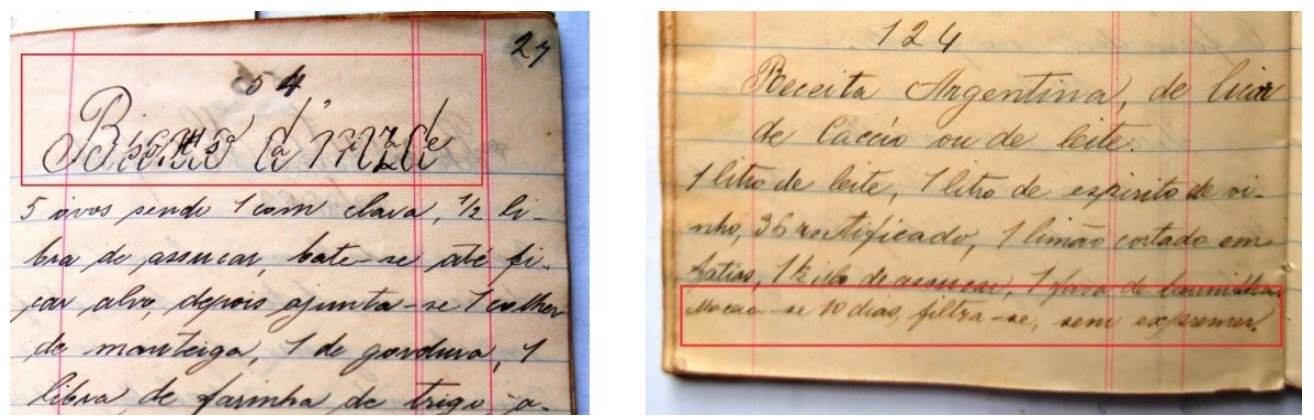

Figura 19 - Trechos do cabeçalho [fól. 16r] e do rodapé [fól. 39v] expandidos para além das margens superior e inferior, respectivamente. 


\subsection{Aspectos paleográficos das receitas novecentistas: ângulo, módulo e peso do traçado}

O ângulo do traçado é depreendido na conexão entre os traços verticais e a horizontalidade da pauta ("escrita perpendicular, tombada à esquerda ou à direita") (Berwanger; Leal ([1995] 2008, p. 107). Em relação à análise da angularidade do traçado da letra das receitas novecentistas, tomamos como exemplo o verso do fólio 19 (figura 20). As barras vermelhas evidenciam a inclinação do traçado para a direita em relação à linha de base.

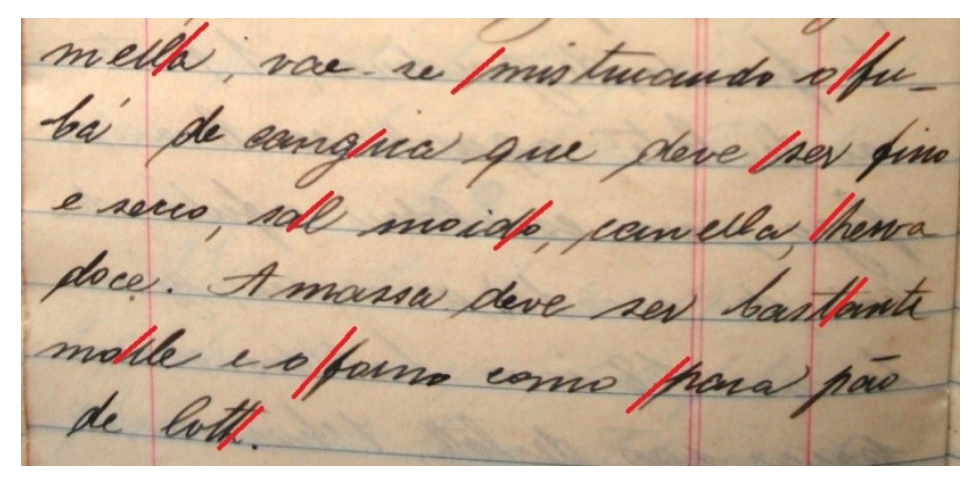

Figura 20 - O ângulo do traçado da letra das receitas culinárias (fól. 19v).

O módulo do traçado pode ser considerado de pequenas dimensões em relação à pauta do suporte, visto que as letras sem hastes cabem no intervalo entre as linhas do caderno de receitas, conforme evidenciam as figuras 21 e 22 . Isso é verificável não só em relação às letras minúsculas baixas, que não atingem a metade da linha, dentro do grupo em que se inserem as vogais, como também no que se refere às próprias hastes das letras minúsculas como o ' $\mathrm{l}$ ', o ' $\mathrm{h}$ ', o 'b' e o ' $\mathrm{t}$ ', mais altas, mas que não chegam até a linha superior. Por outro lado, os grafemas minúsculos 'p', 'f, 'g', 'j' e 'd', cujas hastes são normalmente mais extensas, ultrapassam a linha de base (fól. 21r). As letras maiúsculas variam, podendo alcançar a linha superior, como observamos em relação ao grafema 'B' (figura 21) do título de uma das receitas ("Biscoutinhos de polvilho").

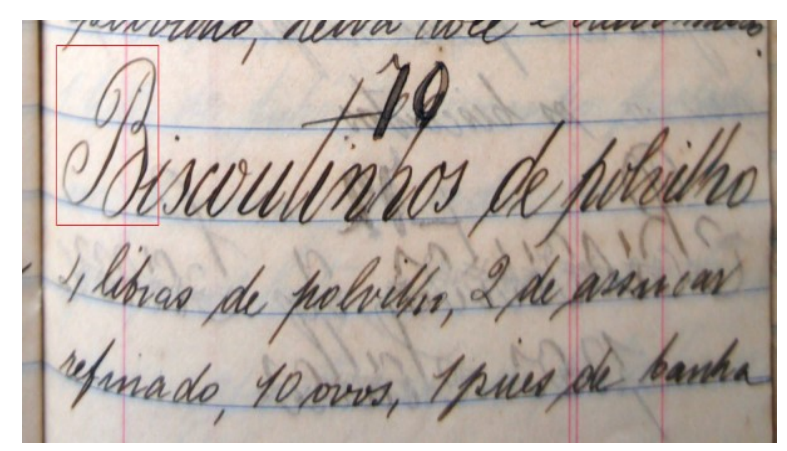

Figura 21 - O módulo do grafema 'B' no título de uma receita [fól. 21r.]. 


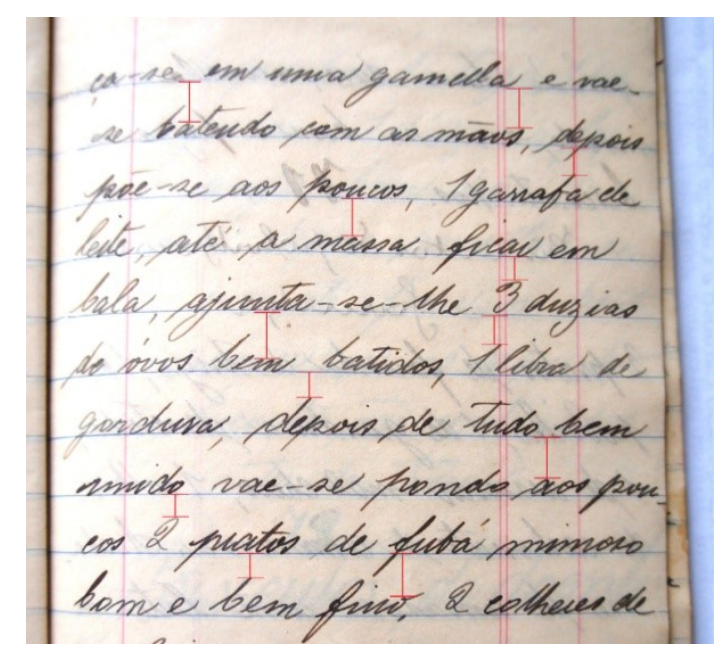

Figura 22 - O módulo do traçado: trecho do fól. 21 r.

O peso do traçado é interpretado como consequência "do peso da mão do escriba no ato de grafar o documento" (Berwanger; Leal, [1995] 2008, p. 107). Em relação às receitas culinárias novecentistas, observamos que o peso do traçado da letra ${ }^{7}$ é fino e claro. Nos títulos das receitas, por outro lado, o peso do traçado parece mais acentuado, evidenciando, em alguns trechos, manchas da redação da palavra no verso do fólio. Em alguns trechos, é possível identificarmos algumas evidências em que o peso do traçado da letra parece fazer-se mais intenso, não só no início das palavras e dos numerais, mas também no final da palavra, como está ilustrado na figura 23.

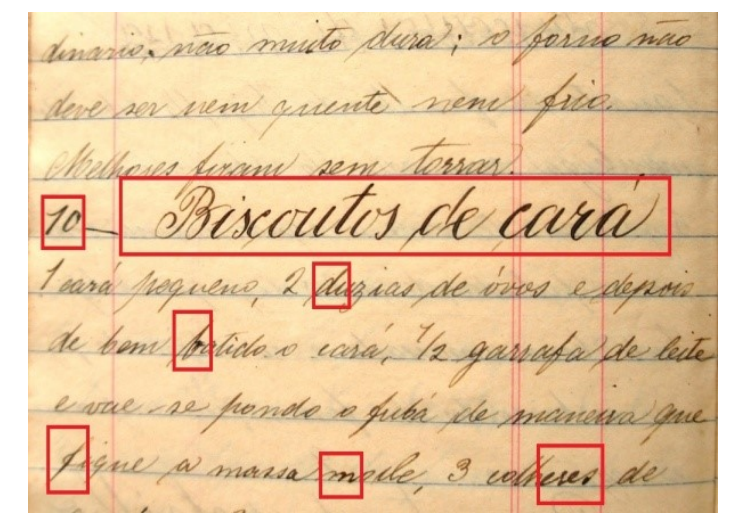

Figura 23 - Comparação entre os pesos dos traçados no corpo do texto, no título, em início de palavras e em numerais (fól. 4v).

Uma vez descritas algumas evidências do ângulo, módulo e peso do traçado, passamos a elencar temas para futuras análises embasadas nas receitas culinárias novecentistas em análise.

\footnotetext{
7 "Espessura da haste da letra, que vai da cabeça ao pé do olho [da letra], incluindo a rebarba [...]" (Faria; Pericão, 1999, p. 279).
} 


\section{CONSIDERAÇÕES FINAIS}

Neste estudo, procuramos evidenciar não só a relevância de conservadoras edições nos formatos fac-similar e semidiplomático para futuros estudos linguísticos, mas também a necessária discussão de aspectos paleográficos do PB escrito no início do século XX. Passamos pela apresentação das normas de edição dos manuscritos e fizemos uma breve descrição analítica de alguns aspectos paleográficos do ductus, relacionados ao ângulo, módulo e peso do traçado. Diante da breve discussão acerca da paleografia de leitura, da paleografia crítico-analitica e da paleografia com foco na bistória da escrita, assumimos, neste texto, o nosso comprometimento com a paleografia de leitura (Nuñez Contreras, 1994) para a descrição de aspectos intrínsecos ao traçado das receitas culinárias novecentistas em análise.

Como proposta de temas para futuras análises linguísticas, vislumbramos a possibilidade de análise das construções com o se (Cavalcante, 2016), tendo em vista o seu comportamento variável a seguir exposto nas figuras 24 e 25 , inclusive do mesmo fólio 13 recto. De (01) a (07), observamos mais evidências da expressão variável das estruturas sintáticas com o se, ora com o se indeterminador, ora com o se apassivador, vinculadas aos mesmos predicadores verbais ("bater", "ajuntar", "por", "fazer", "formar").

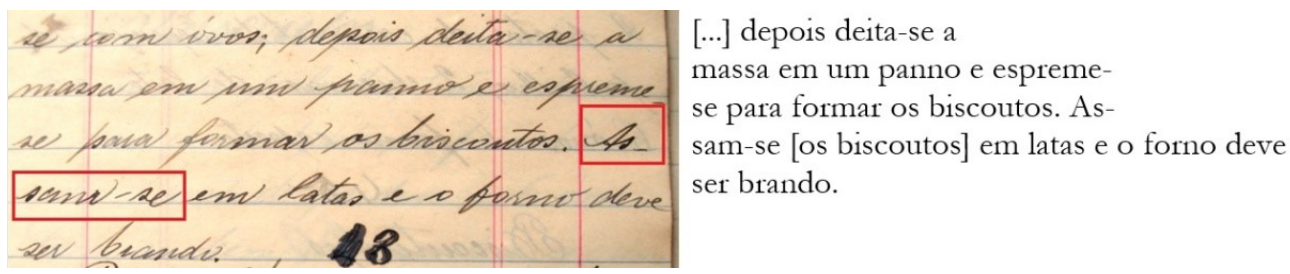

Figura 24 - Fól. 13r: 347-348.

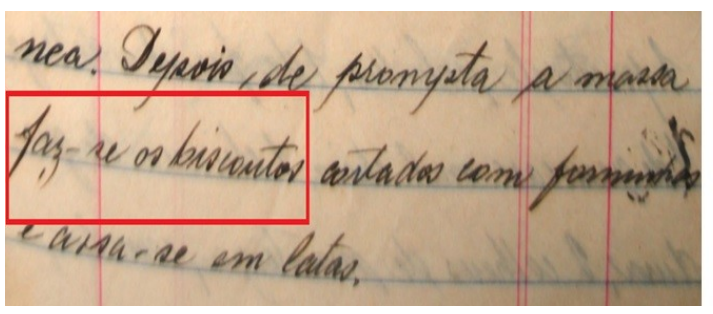

[...] Depois, de prompta a massa

faz-se os biscoutos cortados em forminhas e assa-se em latas.

Figura 25 - Fól. 13r: 357.

(01) "bate-se [...] 15 gemmas" [fól. 23v] e "batem-se 10 gemmas" [fól. 35v];

(02) "batem-se 1 duzia de óvos" [fól. 29r] e "bate-se 1 duzia de óvos" [fól. 23r];

(03) "ajunta-se-lhe 3 duzias" [fól. 21r] e "ajuntem-se 1 libra de assucar" [fól. $29 \mathrm{v}]$

(04) "põe-se no forno os biscoutos" [fól. 24r] e "poem-se os ovos" [fól. 12r];

(05) "faz-se os biscoutos" [fólios 13r, 18v, 19r, 20r, 21v) e "fazem-se os biscoutos" [fól. 25r];

(06) "formem-se os biscoutos" [fól. 24r] e "forma-se os biscoutos" [fól. 26r].

Observamos ainda, de (07) a (09), outras evidências de ausência de concordância verbal com o sujeito sintático pluralizado em estruturas passivas projetadas pelas formas verbais quebrar, ajuntar e untar. 
(07) “[...] quebra-se 2 ovos, sal e doce [...]"

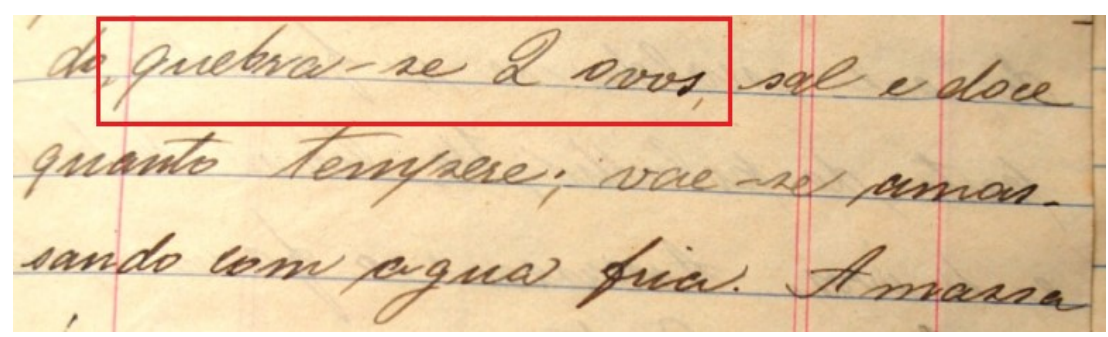

Figura 26 - “quebra-se 2 ovos, sal e doce” [fól. 8r: 193].

(08) “[...] ajunta-se 18 óvos batidos [...]"

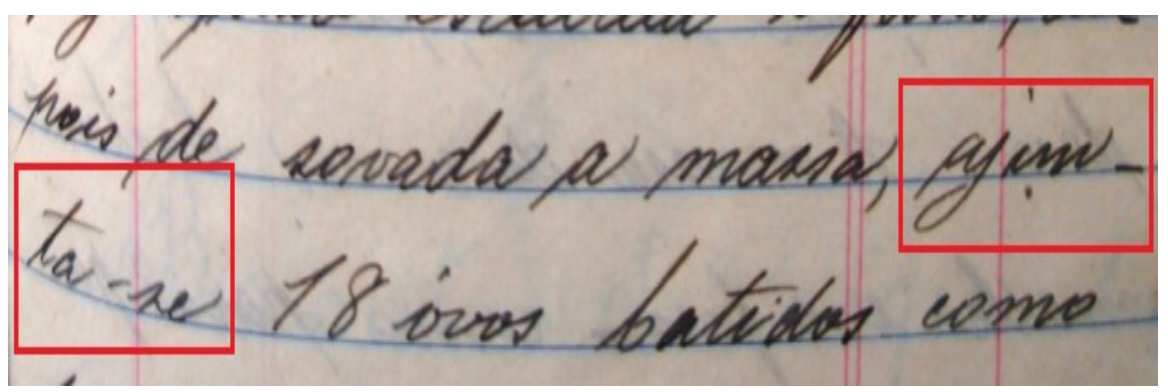

Figura 27 - “ajunta-se 18 óvos batidos” [fól. 19r: 538].

(09) “[...] unta-se as mãos com gordura [...]”

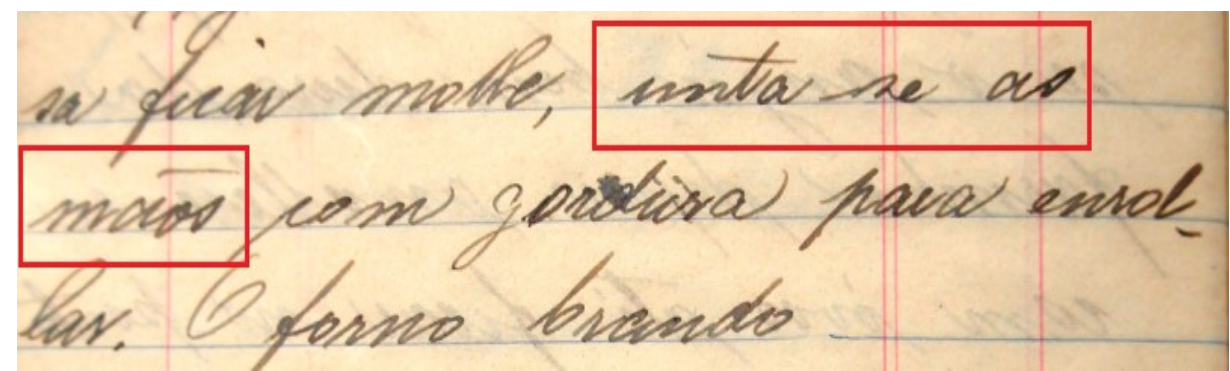

Figura 28: "unta-se as mãos com gordura” [fól. 22v: 634].

Futuras análises linguísticas também podem perpassar pela análise e discussão das etimologizações gráficas, tendo em vista tal aspecto configurar um parâmetro concreto para a mensuração do nível de inserção do escrevente na cultura escrita (Barbosa, 2005, 2008). Como as receitas culinárias em análise são cópias de época (século XX), entendemos que, nesse caso, caberia uma descrição das etimologizações em função das taxas de uso e de acerto por parte da copista, conforme discutido por Barbosa (2005), a fim de fundamentar a discussão acerca do nível de consciência do copista em relação aos traços da cultura escrita. De (11) a (14), ilustramos mais algumas evidências, nas receitas culinárias novecentistas, de grafações etimologizadas verdadeiras por geminadas, em (11), (12) e (13), e falsa, em (14).

(11) gemmas [fól. 4r: 75]: lat. gemma;

(12) gomma [fól. 8r: 189]: lat. tardio gumma;

(13) ammoniaco [fól. 7r: 173]: lat. ammōniăcum -i, deriv. do gr. Ammōniakós;

(14) enrollar [fól 3v: 63]: lat. rotŭlus (rolo). 
Em suma, convém esclarecermos que este estudo paleográfico não se pretende exaustivo. Acreditamos que o resgate das receitas culinárias novecentistas, com base em suas edições fac-similar e semidiplomática, poderá explorar e aprofundar a análise de outros aspectos filológicos, paleográficos e linguísticos acerca da expressão escrita do PB no início do século XX.

\section{REFERÊNCIAS}

Acioli VLC. A escrita no Brasil colônia: um guia para a leitura de documentos manuscritos. Recife: FUNDAJ, Editora Massangana, UFPE, Editora Universitária; 1994.

Barbosa AGB. Tratamento dos corpora de sincronias passadas da língua portuguesa no Brasil: recortes grafológicos e linguísticos. In: Lopes CRS, organizadora. A norma brasileira em construção: fatos linguísticos do século 19. Rio de Janeiro: UFRJ, FAPERJ; 2005. p. 25-43.

Barbosa AGB. Fontes escritas e história da língua portuguesa no Brasil: as cartas de comércio no século XVIII. In: Lima IS, Carmo L, organizadores. História social da língua nacional. Rio de Janeiro: Casa de Rui Barbosa; 2008. p. 181-211.

Berwanger AR, Leal JEF. Noções de paleografia e diplomática. $3^{\text {a }}$ ed. rev. e ampl. Santa Maria: Ed. UFSM; 2008 [1995].

Cambraia CN. Introdução à crítica textual. São Paulo: Martins Fontes; 2005.

Carvalho e Silva M. Crítica textual: conceito - objeto - finalidade. Confluência. 1994;7(1):57-63.

Carvalho e Silva M. A palavra filologia e suas diversas acepções: os problemas da polissemia filologia e crítica textual. Confluência. 2002;23(1):53-70.

Cavalcante SRO. Mudança e estabilidade em construções passivas na história do português. Revista Linguística (Online). 2016;32(1):41-60.

Faria MI, Pericão MG. organizadoras. Dicionário do livro: da escrita ao livro eletrónico. Coimbra: Almedina; 2008.

Labov W. Principles of linguistic change: internal factors. Cambridge: Blackwell Publishers; 1994. Volume I.

Labov W. Principles of linguistic change: social factors. Cambridge: Blackwell Publishers; 2001. Volume 2.

Lima A, Marcotulio LL, Rumeu MCB. Experiências metodológicas em constituição de corpora: pistas para um pesquisador iniciante. In: Castilho AT, organizador. História do português brasileiro: corpus diacrônico do português brasileiro. São Paulo: Contexto; 2019, v. 2. p. 68-91.

Lobo TCF. Para uma sociolinguística histórica do português no Brasil. Edição filológica e análise linguística de cartas particulares do Recôncavo da Bahia, século XIX. Volume II [tese]. São Paulo: Faculdade de Filosofia, Letras e Ciências Humanas, Universidade de São Paulo; 2001.

Nuñez Contreras L. Manual de paleografía: fundamentos e historia de la escritura latina hasta el siglo VIII. Madrid: Cátedra; 1994.

Rumeu MCB. Língua e sociedade: a história do pronome 'você' no português brasileiro, 1ª ed. Rio de Janeiro: Ítaca (FAPERJ); 2013. 
Santiago-Almeida MM. Os manuscritos e impressos antigos: a via filológica. Gil BD; Cardoso EA; Condé VG, organizadores. Modelos de análise linguística. São Paulo: Contexto; 2009. p. 223-234.

Santos MA. Biscoutos, assucar e canella: edição filológica de receitas culinárias novecentistas [monografia]. Belo Horizonte: Faculdade de Letras, Universidade Federal de Minas Gerais; 2018.

Spaggiari B, Perugi M. Fundamentos da crítica textual. Rio de Janeiro: Lucerna; 2004.

Spina S. Introdução à edótica. São Paulo: Cultrix/Editora da Universidade de São Paulo; 1977.

Tarallo F. Diagnosticando uma gramática brasileira: o português d'aquém e d'além mar ao final do século XIX. In: Roberts I; Kato M, organizadores. Português Brasileiro: uma viagem diacrônica. $2^{\mathrm{a}}$ ed. Campinas, São Paulo: Editora da Unicamp; 1993. p. 69-105.

Vasconcellos CA, Santiago-Almeida MM. Contribuição da Filologia e da Crítica Textual para o Estudo de Documentos Manuscritos de Paranaguá. SIGNUM: Estudos da Linguagem. 2012;15(1):335-356.

Weinreich U, Labov W, Herzog MI. Empirical foundations for a theory of language change. Lehmann W, Malkiel Y, organizadores. Directions for historical linguistics. University of Texas Press; 1968. 